\title{
Creativity and Innovation in Haute Cuisine Towards a Systemic Model ${ }^{1}$
}

\author{
Marc Stierand - Viktor Dörfler - Jillian MacBryde
}

\begin{abstract}
The contribution of this study is an increased understanding of personal creativity and the innovation process in haute cuisine, a validation of the socio-cultural systems view of creativity and a model that accounts for the socio-cultural dimensions of haute cuisine. In this paper we discuss existing views that conceptualize creativity and innovation in this sector as a sequential developmental process following the principles of operations management. However, based on in-depth interviews with world-renowned chefs we argue for a systemic rather than sequential developmental process view. The reason for this is that the chefs interviewed understand the 'creativity part' of the innovation process as an embodied experience often guided by intuition and the 'innovation part' as a process of social evaluation greatly dependent on the perception, knowledge and value judgement of the testers from the leading restaurant guides. The main implications of the findings go beyond the haute cuisine sector and open areas for future research on creativity and intuition more generally.
\end{abstract}

Keywords: creativity, innovation, system thinking, haute cuisine

\footnotetext{
1 "This is the peer reviewed version of the following article: Marc Stierand, Viktor Dörfler \& Jillian MacBryde (2014) Creativity and Innovation in Haute Cuisine: Towards a Systemic Model, Creativity and Innovation Management, 23(1): 15-28. DOI: 10.1111/caim.12050, which has been published in final form at http://dx.doi.org/10.1111/caim.12050. This article may be used for non-commercial purposes in accordance with Wiley Terms and Conditions for Self-Archiving."
} 


\section{Introduction}

Historically, haute cuisine has always played a significant role comparable to other industries where the adjective haute (e.g. haute couture) signals trendsetting and the highest quality standards and thus it has a major influence on the image of the restaurant industry as a whole (Stierand, 2013; Surlemont \& Johnson, 2005). Hence, haute cuisine restaurants are expected to be creative and innovative (Balazs, 2001, 2002; Fine, 1992, 1996; Peterson \& Birg, 1988; Rao, Monin \& Durand, 2003; Svejenova, Mazza \& Planellas, 2007; Svejenova, Planellas \& Vives, 2010). Yet, there are few systematic investigations of such restaurants (Lane, 2010) and the academic understanding of creativity and innovation within the sector is at a rudimentary stage (Chesbrough \& Spohrer, 2006) with hospitality managers "often rely[ing] on gut feeling, speculation, and their own limited experience about the keys to innovation success" (Ottenbacher \& Gnoth, 2005: 206).

One of the few conditions that are academically accepted is that creativity is the creation of a new and potentially useful idea and innovation the acceptance of this new idea by those other than the creator (Amabile, 1996b; George, 2007; Zaltman, Duncan \& Holbek, 1973), which means that creativity is a necessary precursor to innovation (Stierand \& Dörfler, 2011a, 2013). The academic world, however, puts a much greater emphasis on researching innovation, without necessarily engaging with creativity, and often conceptualizes innovation as "a continuous, rational and purposive process" (Faullant et al., 2012: 77). This is not essentially different in hospitality research, where the process of turning creations into innovations is generally approached as a sequential development process removed from any socio-cultural influences. Styhre et al. (2010: 134) point to the fact that whilst innovation processes are often described within existing academic literature as linear, "in real-life settings... much decision making in innovation work deviates from such rationalist models".

The main criticism we would like to put forward in this paper is that viewing creativity and innovation in haute cuisine as a sequential development process limits creativity to a manageable exercise of solving well-structured problems and innovation to be merely the creative outcome detached from any socio-cultural impact. Innovation, however, always depends on the social evaluation of the domain gatekeepers (Amabile, 1982, 1983) and creativity, the only necessary component of all innovations (e.g. Popper, 1968), relies on a part of our thinking (lateral or parallel) that is non-algorithmic, which means it "cannot be put into a finite sequence of instructions for solving a problem" (Stierand \& Dörfler, 2011a: 123).

Accordingly, the aim of this article is to critically question the sequential process view by providing a detailed argument and illustrative quotes from in-depth interviews with worldrenowned chefs in support of a socio-cultural model of creativity and innovation in haute cuisine. It is further important to note that in this paper we do not engage with issues of team dynamics in creative teams, and only focus on creativity at expert level (for more on expert level creativity see Dörfler, Baracskai \& Velencei, 2009; Dreyfus \& Dreyfus, 2000; Gobet \& Simon, 2000). 
The article starts by introducing the research approach employed in a study we conducted to elucidate the experiences of personal creativity of 18 world-class chefs in which we also discussed, from the viewpoint of these chefs, the socio-cultural dimensions responsible for turning creations into innovations. This is followed by a section that engages in a critical discussion around whether the work of world-class chefs can and really should be viewed as a sequential development process, or whether it is a more complex and systemic phenomenon. Then we move our argument towards suggesting a more complex, and we believe more adequate, systemic model of creativity and innovation in haute cuisine which is supported by selected interview quotes which demonstrate that the 'creativity part' of the innovation process is described by our interviewees as an embodied experience. The quotes show that the chefs' personal creativity is often guided by intuition whilst innovation is a process of social evaluation, greatly dependent on the perception, knowledge and value judgement of the testers from the leading restaurant guides. Finally, a conclusion is presented and recommendations for future research on creativity and innovation in haute cuisine are proposed.

\section{Research Approach}

The research approach was qualitative and has been conducted through in-depth interviews and through collection of the subjective experiences of the interviewer, which required an inductive and open-ended research design that allowed themes to emerge naturally from the data (Ibarra, 1999; Svejenova, 2005). Potential interviewees were identified based on their listing in Michelin's Guide Rouge and the Gault Millau restaurant guide. Both of these guides are considered to be the most respected in the haute cuisine sector and can be considered as the domain's gatekeepers. The Gault Millau rates restaurants on a 1- to 20-point scale and its ratings are based on "quality of produce; creativity and professionality of preparation; harmony between dishes; menu sequences; exactness of timing in cooking (Garzeit); and presentation" (Lane, 2013: 358). The Michelin guide assigns one to three stars to indicate the culinary excellence of a restaurant with one star indicating a 'good table', two stars being considered worth 'a detour' and three stars worth 'a trip' (Ferguson, 2004) and its ratings are based on quality of preparation and ingredients, consistency of standards, value for money, and the level of creativity (Dixon, 2008; see also Michelin, 2012).

Common to all star-rated restaurants is the external expectation that chefs in these establishments are engaged in personal creativity in order to produce innovative creations (e.g. Balazs, 2001, 2002; Fine, 1992, 1996; Peterson \& Birg, 1988; Rao, Monin \& Durand, 2003; Svejenova, Mazza \& Planellas, 2007; Svejenova, Planellas \& Vives, 2010). This helps to overcome the problem of identifying creative chefs and examining their level of creativity as well as having to find out what makes the creative quality of a chef with one, two, or three Michelin stars or a certain number of Gault Millau points. Ultimately, we were only interested in elucidating experiences of personal creativity that is acknowledged by recognized domain gatekeepers (see Amabile, 1982: 1001; Amabile, 1983: 359) and therefore, as we argued elsewhere (see Dörfler \& Stierand, 2009; Stierand \& Dörfler, 2011b, 2012), we interviewed 
world-class chefs as we assume that rather than representing the general characteristics of the statistical population of chefs, they are more representative of the phenomena of creativity and innovation in their domain.

Interviewees were then selected based on a variety of data sources: the interviewer's personal experience as a chef in haute cuisine restaurants, trade press articles, cookery books and websites of chefs. In total 35 chefs from France, Spain, Austria, Germany, and the UK were contacted of which nine did not reply, seven refused, and 18 agreed to participate. This group comprised two chefs from the UK, four from France, three from Spain, two from Austria and seven from Germany. This ratio is purely the result of a convenience sampling strategy and does not suggest any personal or professional preferences. Table 1 lists all participating chefs by countries, their star rating, and restaurant names.

Table 1: List of interviewees

\begin{tabular}{|c|c|c|}
\hline Chef & $\begin{array}{l}\text { Michelin I Gault Millau } \\
\text { ranking (at time of } \\
\text { research) }\end{array}$ & Restaurant \\
\hline \multicolumn{3}{|l|}{$U K$} \\
\hline Fergus Henderson & $1^{*} \mid \mathrm{n} / \mathrm{a}$ & St John's, London \\
\hline Raymond Blanc & $2 * \ln / a$ & Le Manoir aux Quat'Saisons, Great Milton \\
\hline \multicolumn{3}{|l|}{ France } \\
\hline Jean-Georges Klein & $3 * \mid 18$ & L'Arnsbourg, Baerenthal \\
\hline Michel Troisgros & $3 * \mid 19$ & Maison Troisgros, Roanne \\
\hline Michel Bras & $3 * \mid 19$ & Bras, Laguiole \\
\hline Sébastien Bras & $3 * \mid 19$ & Bras, Laguiole \\
\hline \multicolumn{3}{|l|}{ Spain } \\
\hline Andoni Luis Aduriz & $2 * \ln / a$ & Mugaritz, Errenteria \\
\hline Joan Roca & $2^{*} \ln / a$ & El Celler de Can Roca, Girona \\
\hline Ferran Adrià & $3^{*} \ln / \mathrm{a}$ & El Bulli, Roses \\
\hline \multicolumn{3}{|l|}{ Austria } \\
\hline Heinz Reitbauer & $2 * \mid 19$ & Steirereck, Vienna \\
\hline Roland Trettl & $1 * \mid 18$ & Ikarus im Hangar-7, Salzburg \\
\hline \multicolumn{3}{|l|}{ Germany } \\
\hline Harald Wohlfahrt & $3 * \mid 19$ & Schwarzwaldstube, Baiersbronn \\
\hline Dieter Müller & $3 * \mid 19$ & Dieter Müller, Bergish Gladbach \\
\hline Nils Henkel & $3 * \mid 19$ & Gourmetrestaurant Lerbach, Bergish Gladbach \\
\hline Heinz Winkler & $3 * \mid 19$ & Venezianisches Restaurant, Aschau. \\
\hline Hans Haas & $2 * \mid 18$ & Tantris, Munich \\
\hline Joachim Wissler & $3 * \mid 19$ & Vendôme, Bergisch Gladbach \\
\hline Juan Amador & $3 * \mid 17$ & Amador, Langen \\
\hline
\end{tabular}


The data collection was based on in-depth interviews and a research diary, following the template by Schatzman and Strauss (1973), in which the observational, theoretical and methodological notes were recorded after each interview. The observational and conceptual notes, in particular, were helpful in re-collecting the interviews and provided small pieces of evidence supporting the process of analysis. In addition, we used a number of additional data sources in order to achieve an in-depth understanding of the experience of personal creativity. The full details on the data collection are shown in Table 2.

The interviews relied on a relatively small number of pre-planned topics, aiming at an emergent dialogue that could help elucidate and better understand the interviewees' experiences (see Boje, 1991; Cunliffe, 2002, 2011; Ibarra, 1999). This fluid style of interviewing was possible because of the interviewer's prior experience as a chef in the haute cuisine sector that facilitated building trust and deep conversations between professionals that, with hindsight, would not have been possible without this prior experience, but which, in turn, required a high degree of self-reflection.

Then, the data was analyzed on two levels. For the first level we followed Giorgi's (1985; 1994) method of descriptive phenomenological analysis, because it is particularly suitable for research questions that aim to identify the essential structures underlying the experience of a phenomenon and thus is preferred over other phenomenological approaches that, for instance, aim to capture individual variations between co-researchers (Finlay, 2008; Stierand \& Dörfler, 2012). This first level of analysis was an idiographic descriptive account of the experience of personal creativity from the perspective of the interviewees and includes the identification of elements that blur the invariant but essential nature of the interviewees' experience (see A. Giorgi, 1994; Husserl, 1960). This required us bracketing our preunderstanding and letting several iterations between the data and the reviewed literature take place in order to allow themes to emerge naturally from the interviewees' descriptions.

This first level of analysis provided the necessary transparency for the succeeding interpretive-explanatory level of analysis for which several further iterations took place between the descriptive themes, our own interpretation as reflective practitioner (i.e. chef), the data, and the extant literature. The reason for this interpretive-explanatory analysis was not to find some 'hard proof' but to explain what we have learned about the nature of the experience of personal creativity from the interviewees' accounts and from our own subjective experiences. It is a 'meta-level' of the findings that may be seen as a pattern existing beyond the descriptive findings, or as particular implications of the descriptive findings, their essence, their structure, or loosely coupled associations. 
Table 2: Details on the data collection

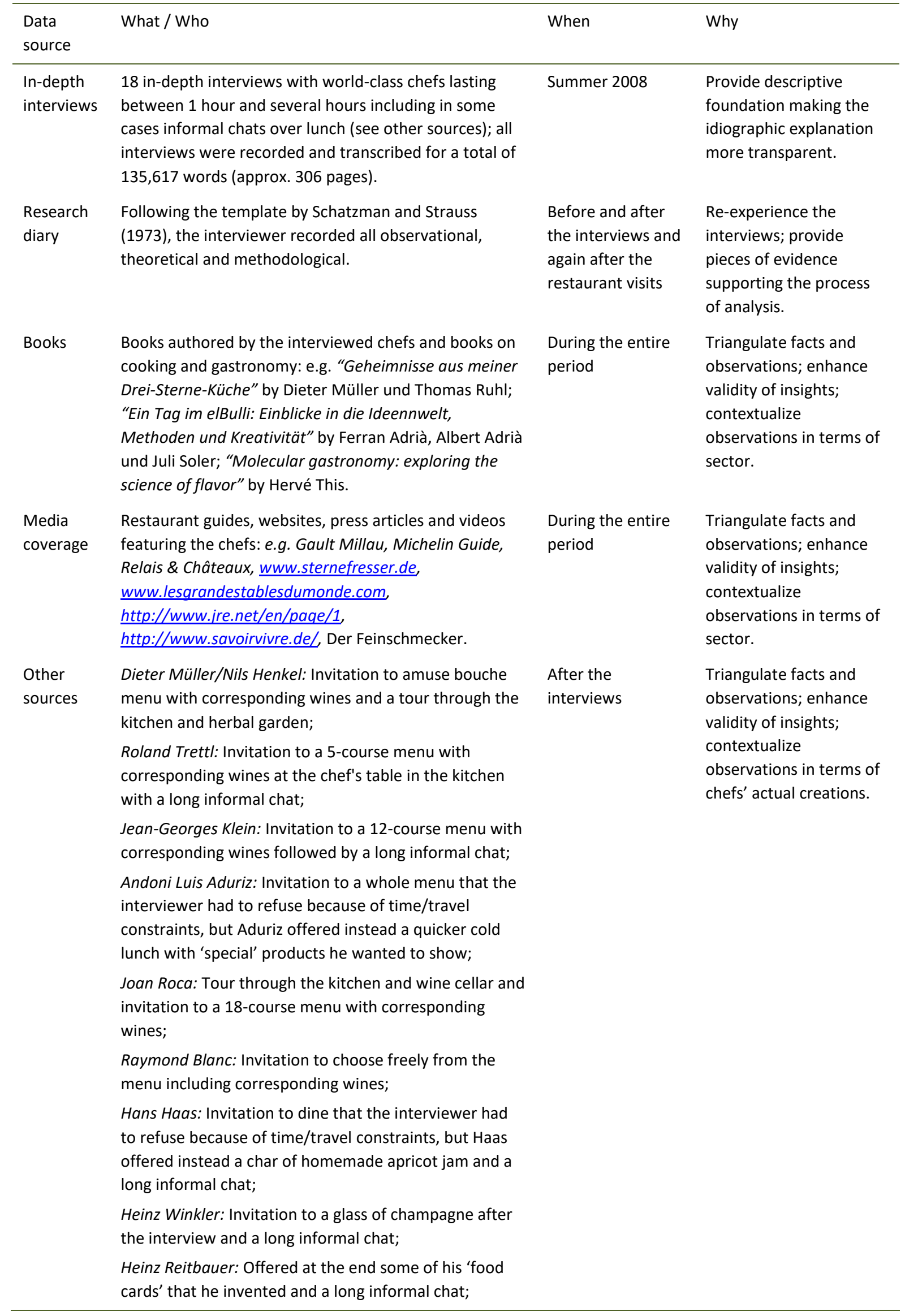




\section{The Problem of Conceptualizing Innovation as a Sequential Process}

Styhre et al. (2010) argue that whilst innovation is often conceptualized as a sequence of linked activities, in "real life" the situation is far more complex. They point to "non-linear" elements in innovation work. And yet the "rational" process-based view of innovation is dominant in the literature. With a small number of exceptions (e.g. Amabile, 1996a; Huber, 1998; Im, Montoya \& Workman, 2013; Keogh \& McAdam, 2004), the majority of studies on innovation in the field of management research focus primarily on technology (see Gallos, 2009: 79), followed by organizational structure (e.g. Pil \& Cohen, 2006; Yang, 2007), knowledge management (e.g. Anand, Gardner \& Morris, 2007), and new product and venture processes (e.g. Song \& Swink, 2002). This situation is quite similar in the field of hospitality research, where studies on innovation focus on development processes (e.g. Ottenbacher \& Harrington, 2007), best practices (e.g. Enz \& Siguaw, 2004), success factors and performance (e.g. Ottenbacher, 2007; Ottenbacher \& Gnoth, 2005), entrepreneurship (e.g. Enz \& Harrison, 2008), innovative behavior (e.g. Orfila-Sintes \& Mattsson, 2009), technology (e.g. OrfilaSintes, Crespí-Cladera \& Martínez-Ros, 2005; Rodgers, 2007; Rodgers, 2008), and the search and recombination of tangible elements instantiated in an innovation (e.g. Messeni Petruzzelli \& Savino, 2012).

Only a small number of hospitality-related studies are interested in studying creativity, but many of these studies focus on concomitant phenomena of creativity, such as barriers and motivators to employee creativity (e.g. Hon, 2011; C.-k. Wong \& W.-L. Pang, 2003; Wong \& Ladkin, 2008; S. Wong \& L. Pang, 2003), phases of the creative process (e.g. Jeou-Shyan Horng \& Hu, 2008, 2009), influential environmental factors (e.g. J-S Horng \& Lee, 2009), intentions to retain or quit a job (e.g. Robinson \& Beesley, 2010), and creative freedom and business model development (e.g. Svejenova, Planellas \& Vives, 2010).

Those that acknowledge creativity in culinary work, within the linear approach to innovation, repeatedly speak of an "innovation development process" (see e.g. Ottenbacher \& Harrington, 2007: 445-446) and define it, based on Cooper and Edgett (1999), as "a formal blueprint, roadmap or thought process for driving a new project from the idea stage through to market launch and beyond" (Ottenbacher \& Harrington, 2007: 445-446). However, Cooper and Edgett (2008) refer to a new product development process, which they call Stage-Gate process. Here, stages consist of a set of necessary or suggested best-practice steps that are essential to bring a project to the next gate. Gates, in turn, are go/kill decision points that serve as quality-control and prioritization decision points. However, the authors are very clear in stressing that the Stage-Gate ${ }^{\circledast}$ process is not to be confused with a functional, phasedreview process, a rigid, lock-step process, a linear system, a project control mechanism, a dated, stagnant system, a bureaucratic system, a data entry scheme, a back-end or productdelivery process, and/or the same as project management (see Cooper, 2008: 215-218).

A further common characteristic of many studies is that they ignore the socio-cultural influences that constitute the system in which creativity and innovation takes place. In psychology research these socio-cultural influences are much more commonly integrated 
(Hennessey \& Amabile, 2010), which may result from the fact that psychologists rarely isolate innovation from creativity, but instead conceptualize it as part of the wider creativity phenomenon of creating a new and valuable idea (i.e. creativity) and then realizing a new value from this idea (i.e. innovation) (Dörfler, Baracskai \& Velencei, 2010).

The socio-cultural model of creativity is widely used in psychology (e.g. Csíkszentmihályi, 2002, 2006; Gardner, 1998) and was introduced in 1983 by social psychologist Teresa Amabile. After an examination of personality tests, which at the time were used to measure an individual's originality (Sawyer, 2006), Amabile (1983) came to the conclusion that originality was not measured objectively and that these tests relied on the implicit subjective assessment of a group of raters, who use their own criteria to simply score a person's originality. She therefore proposed a consensus-based definition of creativity that states that "a product or response is creative to the extent that appropriate observers independently agree it is creative" defining appropriate observers as those that are "familiar with the domain in which the product was created or the response articulated" (Amabile, 1982: 1001; 1983: 359). Hence, Amabile argued that creativity (and innovation) research could never avoid the criterion of social appropriateness, a radical thought that, according to Sawyer (2006), led practically to a complete break with personality trait approaches to creativity.

The idea of a socio-cultural model of creativity was then further developed by Csíkszentmihályi $(1988,1990,1998)$, who introduced the systems model of creativity with its three inter-related parts: the individual, the domain, and the field (Csíkszentmihályi, 1997, 2006). The individual creator is guided by personal creativity, which consists of the individual genetic makeup, talent and experience. Personal creativity is what Csíkszentmihályi calls 'creativity with a small $C^{\prime}$ as opposed to 'creativity with a capital $C$ ', which represents the outside environment that consists of the domain, with its specific rules, knowledge, tools, practices and values, in which the individual has chosen to work, and the field that consists of the persons and institutions that judge the creative quality of the individual's work. In other words, the field are those people or institutions that Amabile calls 'appropriate observers'. Thus, Csíkszentmihályi (1997: 27-28) suggests at aiming to understand where creativity happens rather than what it is by distinguishing between creativity (with a lower case c) and Creativity (with a capital C). The former is concerned with the creation of a new and valuable idea and the latter with realizing a new value and thus Creativity (with a capital C) resembles what is called innovation in management and business research (Dörfler, Baracskai \& Velencei, 2010).

In the next section we provide arguments and power quotes from our interviewees in support of the non-linearity of creativity. We refer several times to the constructs of emotions and intuition, because both of these play an important role in creative work. However, we do not suggest that emotions and intuition are the two guiding principles that define creativity. The reasons why we refer to them is that they do characterize personal creativity, they are both highly non-linear processes and usually acknowledged as such (see 
Simon, 1987, on the description of the decision-making process), and because the interviewees related to these constructs with ease.

\section{Towards a Systemic Model of Creativity and Innovation in Haute Cuisine}

In hospitality research the concept of culinary innovation is often used interchangeably with the concepts of culinary products and culinary product development by arguing that "all of these concepts reflect innovative food items consumed in a foodservice establishment" (Harrington, 2004: 36; see also Ottenbacher \& Harrington, 2007). We think that it is problematic to use these concepts interchangeably in the haute cuisine context. The reason for this is that by adopting an operations management perspective, which in our view is the only justification for such understanding of innovation, implies that one accepts efficiency, total cost, lead time and capacity utilization as the guiding performance metrics and supplier and material selection, production sequence design and project management as the prevalent critical success factors (see Krishnan \& Ulrich, 2001: 3). Such perspective, however, seems not to be the predominant guiding principle described by the chefs we have interviewed. Raymond Blanc, for example, pronounced very vividly:

"It is essentially for it! You work for the sake of beauty, to touch excellence - even if it is for seconds, between seconds. You want to go to the heart. When you do a dish, or a new environment, or a new breakfast, or whatever it is, it is for it and for the sake of our guests. And the by-product of that is, of course, that it will make you so much happier!" (emphasis added)

Similarly, Michel and Sébastien Bras stated that chefs at the highest level of cooking are obsessed with creating the ultimate experience that reflects novelty, aesthetics and cleverness, because only when this is achieved they feel happy and such an experience can only be achieved if one's work is guided by feeling to begin with. The aspect that creativity holds emotional and satisfying rewards for the creator is well-documented in the psychology literature on creativity. Csíkszentmihályi (1997: 2), for example, remarks that being involved in creativity feels as if life is lived more fully and "perhaps only sex, sports, music, and religious ecstasy [...] provide as profound a sense of being part of an entity greater than ourselves".

Hence, we argue that by employing an operations management lens that allows the concepts of innovation, product and product development to be used interchangeably, the process of creativity and innovation in haute cuisine becomes a manageable well-structured problem solving exercise, similar to those often found in industrial settings following a traditional project management approach based on the ideas of Gantt and Fayol. But, what do we mean by 'manageable well-structured problem solving exercise'? Herbert Simon (1973: 183) distinguished between ill-structured and well-structured problems and described the latter with six conditions; if any of these is missing, the problem is ill-structured: (1) there exists definite criteria to test the solution; (2) the initial problem state, the goal state and all 
intermediate states may be represented; (3) the transitions between the previous states can be represented; (4) the acquired knowledge can be represented; (5) the effects of the environment can be represented; and (6) a feasible amount of search and computing is required.

Well-structured problems are thus tasks rather than problems and are completed rather than solved whereas ill-structured problems can be understood as knowledge gaps and thus their solutions always require creativity (Baracskai, 1998; Dörfler, Baracskai \& Velencei, 2010; Stierand \& Lynch, 2008). This means, in turn, that new ideas are only considered creative when they provide a new and valuable solution to a problem (Amabile, 1996b; Dörfler \& Ackermann, 2012; Johansson, 2006), which highlights the systemic nature of innovation, because whether a new idea is also considered valuable is decided by the appropriate observers of the domain (Amabile, 1982, 1983), which was also confirmed by the interviewees.

"...be it scallops or ramsons, things that are frowned upon by critics since years, ... I don't use such things!" (Heinz Reitbauer)

"What did the Gault Millau write? Zero creativity, but everything was fantastic! Something like that. But this statement says everything: if the food would have been too creative it might not have been so good!... I have never seen a person who continuously has new ideas" (Heinz Winkler)

The belief that creative people are an endless source of new ideas is probably as delusive as the academic ambition to describe creativity and innovation in simple, sequential and manageable steps. Wallas' (1926), for example, proposed a 4-stage model of the creative process in which he suggests that any creative process consists of a preparation, incubation, inspiration, and evaluation phase. Whilst numerous creativity researchers have adopted Wallas' model at least in parts (e.g. Jeou-Shyan Horng \& Hu, 2008, 2009; Norlander \& Gustafson, 1997, 1998), there remains considerable criticism about the superficiality of such process description. Guilford (1950), for example, criticized Wallas' model for failing to take into account any mental operations that occur during the creative process. Hence, any approach that anchors creativity and innovation in an operations management framework must assume, admittedly to varying degrees, that all people are (and can be) predominantly rational and that a process of creativity and innovation is a well-structured and probably (or preferably) a sequential process. If this assumption would not be accepted from the outset, operations management would not work.

The chefs interviewed, however, did not confirm the existence of such a well-structured process of creativity. Harald Wohlfahrt, for instance, stressed that creativity needs space to develop, a free mind and the freedom to make mistakes, which is often impossible in the dayto-day running of a restaurant. In his view creativity cannot be forced, which is reflected in the fact that sometimes he has several ideas in one week and sometimes none for a month. For him, creating is a continuous development over many years in aim of pushing the 
boundaries towards perfection. This was also confirmed by Andoni Luis Aduriz, who distinguished between creativity when creating and 'creative' improvisation during the service. The latter he only accepts as a tool to quick-fix problems during the service, because the results of improvisation will never be exceptional. The reason for this is, according to Aduriz, that creativity cannot be controlled and standardized. Therefore, the craft became such an important element in cooking because it is the only part that can be controlled and which acts as protection of the initial creative idea during operations:

"We put the sauces in test tubes, we don't reduce them, we don't put salt so that you can't mistake them for anything. So, at the moment we are putting them to the plate, you can't possibly put more or less and the temperature is controlled" (Andoni Luis Aduriz).

Of course, operations management has achieved great successes and has proven to be extremely useful in those areas where we are faced with routine and to a certain degree adaptive decisions, however, as e.g. Mason and Mitroff (1973) argue, traditional operations management fails to translate its successes into areas of greater complexity where we are faced with innovative decisions that address novel problems for which we lack any prespecified courses of action. In other words, because the problems are ill-structured, the problem-solver requires creativity, but creativity is exactly what cannot be modelled (or operationally managed for that matter) in a well-structured way, because there is no such thing as a rational method reconstructing the process of having ideas since every (inner) 'discovery' contains "an irrational element", or "a creative intuition", in Bergson's sense (Popper, 1968: 8).

Generally, it is unlikely that haute cuisine unveils problems that require urgent solving from a societal perspective, but economically, haute cuisine restaurants are under immense pressure to create value by capitalizing on personal creativity, which is generally regarded as the most important resource contributing to the creative output of firms (Althuizen, 2012; Kabanoff \& Rossiter, 1994). Even more so, personal creativity in haute cuisine is of particular importance, because restaurants in this sector are representative of the creative industries (Ferguson, 1998; Petruzzelli \& Savino, 2014; Svejenova, Slavich \& Abdel-Gawad, 2012), which means that their creative output is decisive as to whether they are able to create or maintain a sustainable competitive advantage (see Chaston \& Sadler-Smith, 2012; DCMS, 2001; NOIE, 2003).

Value in haute cuisine, however, does not necessarily mean that a new idea solves a specific problem, but instead may simply create an effective surprise that is aesthetically pleasing (see Runco, 2006). The notion of 'effective surprise' as well as emotion, was central to the chefs interviewed. Ferran Adrià, for example, noted that the highest gastronomic experience is to create a direct line of communication between creator and receiver with the aim to create happiness. One way of awakening such emotions is, according to Michel Troisgros, to create food that triggers childhood memories; another, according to Raymond Blanc, is to utilize the emotions one has when being head over heels in love with someone: 
"I am doing a dessert now for my girlfriend and I am looking for new and fine textures. So, it is going to be hundreds of thousands of leaves that are going to be crunchy and in between some powerful little notes." (emphasis added)

Thus, it is reasonable to assert that the creative process, as described by our interviewees, is very much an embodied experience that is often guided by intuition (Dane \& Pratt, 2009; Dörfler \& Ackermann, 2012; Sinclair, 2011). Embodied experience refers to the character of the sensemaking process from inspiration to idea generation. Traditionally, sensemaking is regarded as a cognitive activity by which information is processed (Cunliffe \& Coupland, 2012) in a rational-intellectual way based on existing cognitive models and schemas (Chaudhry, Wayne \& Schalk, 2009; Grant, Dutton \& Rosso, 2008; Jeong \& Brower, 2008). Weick was formative in explaining that sensemaking is an iterative process between a socially constructed and interpretive understanding of the environment aiming to introduce "stability into an equivocal flow of events by means of justifications that increase social order" (Weick, Sutcliff \& Obstfeld, 2005: 15).

The sensemaking process that our interviewees described has an embodied character and involves a large degree of bodily sensations and sensory knowing (see Cunliffe \& Coupland, 2012). Harald Wohlfahrt, for example, mentioned that he often develops new ideas when engaged in ordinary everyday activities, such as deboning a saddle of lamb. A plausible explanation for this phenomenon is that sensory knowing, or intuition, works well during activities for which we have learned to automatize the tools required to execute these activities (Sadler-Smith, 2008). Tsoukas (2005) says that the tools become 'amplifiers' of the senses and then intuition can become a valid form of knowing.

"The great chefs have that unspoken understanding. They know! They know that was a great chef! That means their intuition is so high, their knowledge of food is so high, they are so much in love with their food, they are able to touch their food and almost do things intuitively." (Raymond Blanc)

In this paper we use the broad conceptualization of intuition (for a historical overview see Akinci \& Sadler-Smith, 2012; Osbeck, 1999) as the human capacity of 'direct knowing' (Behling \& Eckel, 1991; Osbeck, 2001; Sinclair, 2011), a 'knowing without knowing how' (Vaughan, 1979). Thus, the type of sensemaking used by our interviewees goes beyond its traditional understanding of being a purely linear and retrospective activity of translating data into knowledge (see Weick, 2001). In other words, embodied sensemaking is a kind of indwelling, which provides an inner 'guiding force' that helps to respond to experiences and interpret them into creative ideas (see Polányi, 1969; Tsoukas, 2005) that carry an emotional quality.

Ferran Adrià, however, stressed that creating emotions is incredibly difficult and requires knowledge both on the creator's and the perceiver's side. According to him, 
emotions can occur on three levels: the first is the level of basic animal emotions; the second is the level of intellectual or reflexive emotions; and the highest level are creative emotions. The latter are the most complex to understand and require substantial knowledge from the creator. In turn, the receiver must be interested in the creation and must at least have some fundamental knowledge of it in order to receive the emotion. Adrià referred here to Picasso's Demoiselles d'Avignon by saying that this painting changed the history of art, but that one has to know that it was the first introduction of Cubism in order to be able to evaluate its creativity qualities. This shows the complexity of the systemic nature of innovation, because the 'ordinary consumer' may lack the knowledge to recognize the quality of an idea and therefore a chef must be truly convinced of the idea in order to ensure that it is worth pushing it through the process of social evaluation.

This process is a kind of filtering whether the new idea "will fit regarding the expectations of the environment" by distinguishing "what is new (i.e. unknown)" from "what is old (i.e. known)" (Pohlmann, 2005: 10) and such a process is "not a linear process with "key success factors' but rather a whirling process" (Paget, Dimanche \& Mounet, 2010: 843). Hence, we argue that it is not enough to just create something based on a sequential development process at which end the current taste of the audience is met. It is much more a balancing act of translating the known into something new and potentially useful and in this process chefs are constantly playing in the vanguard of culinary practice and gastronomy (Stierand, 2013).

"... comparing the cooking here with home-cooking is like comparing a Formula 1 car with an old Daimler with which you cruise and enjoy the scenery... The two have absolutely nothing to do with each other... It is absolutely not like home-cooking and it is not familiar cooking!" (Ferran Adrià)

Of course, one could argue that the above quote by Ferran Adrià is not representative because he is an extreme example of creativity in the domain. But, is the work of a classical composer less creative than the one composing jazz? In fact, this question was very important to the interviewees, because some widely recognized 'old masters' struggle to keep up with current expectations of creativity imposed by parts of the media and restaurant testers. These field gatekeepers fashionably misuse trends, such as molecular gastronomy, by forcing chefs to engage in a form of largely excessive hyper-creativity that often tends to emphasize the photogenic appearance of food over taste (Stierand, 2013).

It is a complex process until a new idea gets accepted by the field, because it happens in the "interaction between a person's thoughts and a sociocultural context" (Csíkszentmihályi, 1997: 23). In particular some of the long-serving chefs interviewed were concerned about the current media climate and its lack of accepting and applying constructive criticism. 
"The young people are getting praised for everything they do. I just said to someone that if you cook pig's ears in chocolate sauce everybody says 'it is wonderful', because nobody has the guts to say something about it! Everybody is afraid to be considered not being 'up-to-date', closed-minded, or not innovative, and this is how we get food that is certainly not good!" (Heinz Winkler, emphasis added)

More worrying are the accounts provided by Hans Haas and Juan Amador. Both of them highlighted a particularly unprofessional behaviour of some restaurant testers who live from telling a new 'hot' story in their guides and in order to do so they personally attack chefs (see Woodward \& Stierand, 2014). As we will explain more momentarily these gatekeepers are highly influential in the process of social evaluation.

"One of the most famous hoteliers in [country xyz] and the boss of the [xyz guide], who is also the godfather of this hotelier's son, together regularly visit younger colleagues, which is something you just don't do if you have such a friendship! And I know from other colleagues who told me that these two gentlemen explicitly go to younger chefs so that they can tell them how rubbish they cook... This is well known in the scene! I find it just roguery, but nobody has the guts to say something... to be the friend of the Editor-inChief and to go to the restaurants of colleagues... giving them miserable critiques and sometimes even score them low on purpose, this shows a very poor character." (anonymized, emphasis added)

The purpose of this discussion was to illustrate why the so-called innovation development process' is, in our view, a less adequate description of the process of creativity and innovation in haute cuisine than the systems view we advocate in this paper. Based on our argument and the provided illustrative interview excerpts we propose the following model (see Figure 1) as a new starting point for further research on the topic and invite other researchers to comment on our reasoning and/or extend the model based on their empirical observations.

The central figure of our model is the creative chef. There are two relationships of the chef in harmony with Csíkszentmihályi's model: one with the domain (Haute Cuisine culture) and one with the field (customers). Apart from naming the three players for our specific case, we have also added details of the aforementioned relationships: the creative chef is advancing the knowledge of the domain through their creations while the engagement with the field is a commercial one through the dining of the customers. In haute cuisine we have an additional player and this is exactly what makes haute cuisine an excellent area for investigating creativity: there is an institutionalization of the gatekeeper function in the form of the restaurant guides (in particular the Michelin Guide and the Gault Millau). These gatekeepers have a central role in facilitating but also modifying the previously described relationships. On the one hand, they evaluate the ideas of the chefs, and these evaluations have profound significance. On the other hand, by assigning high value to particular ideas 
they influence the domain of haute cuisine and may have substantial effect on the direction of the progress. This does not mean that they decide which way the domain will develop but they certainly influence it. On the other hand, the customers have high regard for e.g. the Michelin stars and the Gault Millau scores, so a three-star Michelin restaurant can set higher prices than a one-star thus the commercial viability of the chefs significantly depends on these gatekeepers. Therefore it is clear that the gatekeepers modify the relationships in this systemic model of creativity but their operations are sufficiently clear that their effect helps rather than hinders our understanding of the real-world processes.

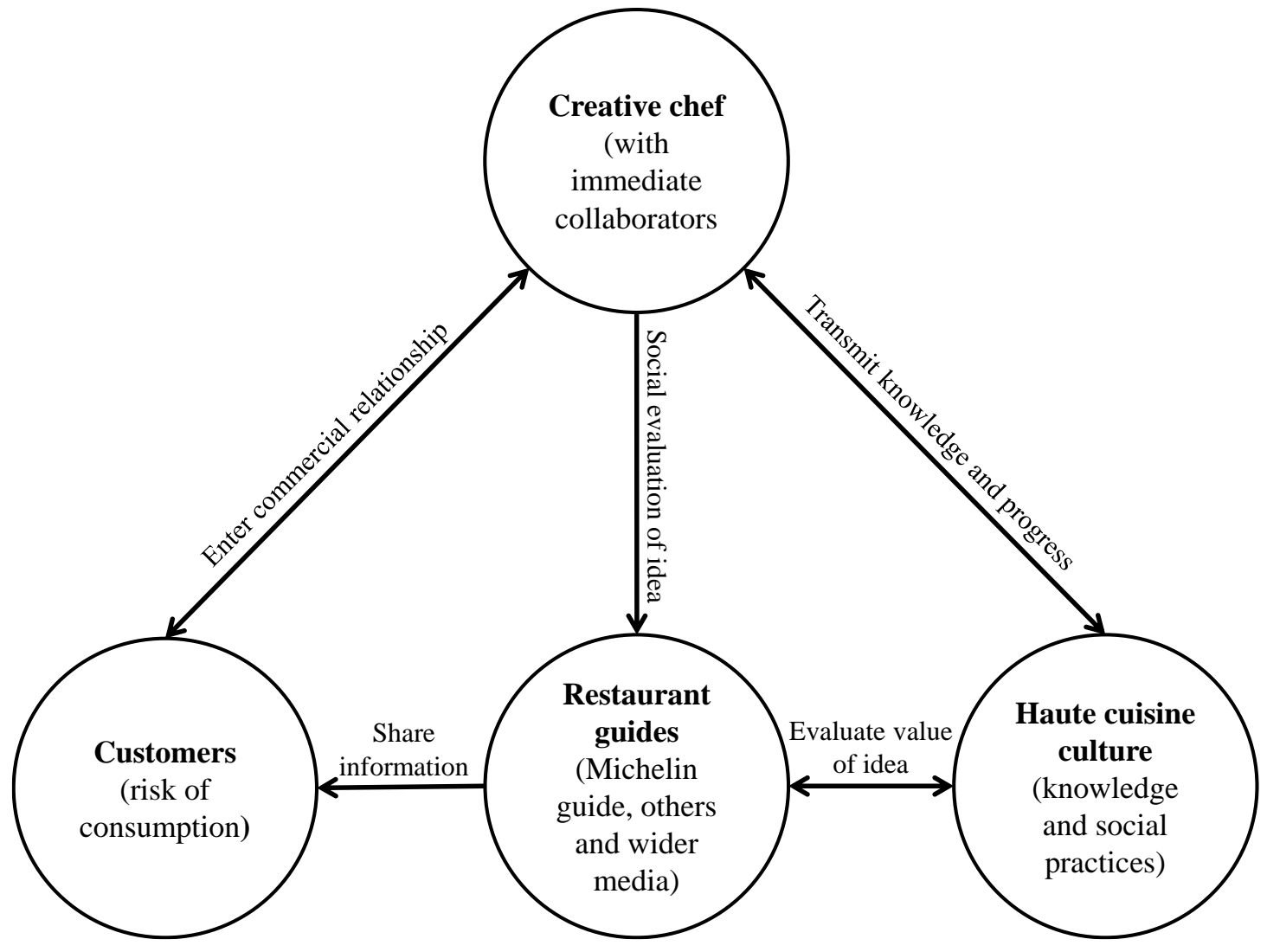

Figure 1: Systemic model of creativity and innovation in haute cuisine

\section{Conclusion}

Despite consistent calls for a systems view of creativity and good progress in social psychology (Hennessey \& Amabile, 2010), researchers (particularly in the wider field of management) have shown a tendency to study exclusively the 'creativity of new products' (Im, Montoya \& Workman, 2013: 171) or to focus on innovation as "a continuous, rational and purposive process" (Faullant et al., 2012: 77). Research on the creative ability of the individual, for example, is scarce, although it is widely acknowledged that it is the single most important factor contributing to the innovative output of firms (Althuizen, 2012; Kabanoff \& Rossiter, 1994). In response to these shortcomings, the consistent calls from social psychology to 
adopt a systems view, and recent calls from management research to move towards systemic studies (see Özbilgin, 2011), we have built on Amabile's and Csíkszentmihályi's socio-cultural systems view and provided a detailed argument and illustrative quotes from in-depth interviews with 18 world-class chefs that support our view that creativity and innovation in haute cuisine is not a sequential development process.

The contribution of the paper is an increased understanding of personal creativity and the innovation process in haute cuisine, a validation of the socio-cultural systems view of creativity as well as a proposal of a creativity and innovation model that accounts for the socio-cultural dimensions of the haute cuisine sector. From the study on personal creativity of world-class chefs we have learned that current conceptualizations of creativity and innovation in haute cuisine are strongly guided by the ideas of operations management and do not represent the predominant guiding principles of creativity and innovation described by the chefs we have interviewed. Our study shows that the 'personal creativity part' of the innovation process is an embodied experience that is often guided by intuition and that the 'social evaluation part' of the innovation process always depends on the perception and knowledge of the domain gatekeepers to recognize the quality of an idea. This clearly shows the complexity of the systemic nature of innovation.

The main implications of the findings go beyond the haute cuisine sector and open areas for future research on intuition and knowledge in general. Future research could therefore focus on better understanding how creative people liberate themselves from their 'inherited background' (e.g. culture of haute cuisine domain) (see Wittgenstein, 1979) or any learned plan of action (see Deleuze, 1988; Rooney, 2004), or explore how people in different occupations (e.g. managers or product developers) respond creatively and dynamically to lived experiences (see Clegg, Kornberger \& Rhodes, 2005) by embodied and intuitive sensemaking.

Finally, we would like to acknowledge the main limitations of the study. The research approach was interpretive and only male chefs from five European countries were interviewed. For that reason we intend to conduct further research aimed at elucidating the experiences of creative chefs, both female and male, from other countries, in particular those from non-Western countries and we aim to extend our research to additionally investigate creative individuals from various domains. 


\section{References}

Akinci, C \& Sadler-Smith, E (2012) Intuition in Management Research: A Historical Review, International Journal of Management Reviews, 14(1): 104-122. http://dx.doi.org/10.1111/i.1468-2370.2011.00313.x

Althuizen, N (2012) The relative performance of different methods for selecting creative marketing personnel, Marketing Letters, 43(4): 973-985. http://dx.doi.org/10.1007/s11002-012-9198-x

Amabile, TM (1982) Social Psychology of Creativity: A Consensual Assessment Technique, Journal of Personality and Social Psychology, 43(5): 997-1013. http://dx.doi.org/10.1037/0022-3514.43.5.997

Amabile, TM (1983) The Social Psychology of Creativity: A Componential Conceptualization, Journal of Personality and Social Psychology, 45(2): 357-376. http://dx.doi.org/10.1037/0022-3514.45.2.357

Amabile, TM (1996a) Creativity and Innovation in Organizations (Harvard Business School Background Note, No. 396-239), Harvard Business School, Cambridge, MA.

Amabile, TM (1996b) Creativity in Context: Update to the Social Psychology of Creativity, Westview Press, Boulder, CO.

Anand, N, Gardner, HK \& Morris, T (2007) Knowledge-based innovation: emergence and embedding of new prctice areas in management consulting firms, Academy of Management Journal, 50(2): 406-428.

Balazs, K (2001) Some like it haute: leadership lessons from France's great chefs, Organizational Dynamics, 30(2): 134-148.

Balazs, K (2002) Take One Entrepreneur: The Recipe for Success of France's Great Chefs, European Management Journal 20(3): 247-259.

Baracskai, Z (1998) Profi problémamegoldó (Master of Problem Solving), "Szabolcs-SzatmárBereg megyei Könyvtárak" Egyesülés, Nyíregyháza, Hungary. [Published in Hungarian]

Behling, O \& Eckel, NL (1991) Making Sense out of Intuition, Academy of Management Executive, 5(1): 46-54. http://dx.doi.org/10.5465/AME.1991.4274718

Boje, D (1991) The storytelling organization: A study of story performance in an office-supply firm, Administrative Science Quarterly, 36(1): 106-126.

Chaston, I \& Sadler-Smith, E (2012) Entrepreneurial Cognition, Entrepreneurial Orientation and Firm Capability in the Creative Industries, British Journal of Management, 23: 415432.

Chaudhry, A, Wayne, SJ \& Schalk, R (2009) A Sensemaking Model of Employee Evaluation of Psychological Contract Fulfillment When and How Do Employees Respond to Change?, The Journal of Applied Behavioral Science, 45(4): 498-520. 
Chesbrough, H \& Spohrer, J (2006) Services Science: A Research Manifesto [Electronic Version], 1-10. Retrieved 11 November 2006 from www.sbs.ox.ac.uk/.../99F135D4E982-4580-9BF0-

8515C7B1D40B/1754/ServicesScienceManifestoCACMv820060320.doc.

Clegg, S, Kornberger, M \& Rhodes, C (2005) Learning/Becoming/Organizing, Organization, 12(2): 147-167.

Cooper, R (2008) Perspective: The Stage-Gate Idea-to-Launch Process. Update, What's New, and NexGen Systems, Journal of Product Innovation Management, 25: 213-232.

Cooper, R \& Edgett, S (1999) Product Development for the Service Sector, Perseus Books, Cambridge, MA.

Csíkszentmihályi, M (1988) Society, Culture, and Person: A Systems View of Creativity, Sternberg, RJ \& Davidson, JE Conceptions of Giftedness, Cambridge University Press, New York, NY: 325-339. http://dx.doi.org/10.1007/978-94-017-9085-7 4

Csíkszentmihályi, M (1990) The Domain of Creativity, Runco, MA \& Albert, RS Theories of creativity, Sage Publications, Thousand Oaks, CA: 190-212.

Csíkszentmihályi, M (1997) Creativity, HarperCollins, New York, NY.

Csíkszentmihályi, M (1998) Implications of a Systems Perspective for the Study of Creativity, Sternberg, RJ Handbook of Creativity: , Cambridge University Press, Cambridge: 313336. https://www.cambridge.org/core/books/handbook-of-creativity/implicationsof-a-systems-perspective-for-the-study-ofcreativity/BCA7855B084885FA9C8336BBA86820B1

Csíkszentmihályi, M (2002) Flow: The Psychology of Optimal Experience (2nd ed.), Rider, London.

Csíkszentmihályi, M (2006) A Systems Perspective on Creativity, Henry, J Creative Management and Development (3rd edition), Sage, London: 3-17.

Cunliffe, A (2002) Social poetics: A dialogical approach to management inquiry, Journal of Management Inquiry, 11(2): 128-146.

Cunliffe, A (2011) Crafting Qualitative Research, Organizational Research Methods, 14(4): 647-673.

Cunliffe, A \& Coupland, C (2012) From hero to villain to hero: Making experience sensible through embodied narrative sensemaking, Human Relations, 65(1): 63-88.

Dane, E \& Pratt, MG (2009) Conceptualizing and Measuring Intuition: A Review of Recent Trends, Hodgkinson, GP \& Ford, JK International Review of Industrial and Organizational Psychology (Vol. 24), Wiley, Chichester, UK: 1-40. http://media.wiley.com/product data/excerpt/08/04706800/0470680008.pdf 
DCMS (2001) Creative Industries Mapping Document 2001, retrieved 4 May, 2007, from http://www.culture.gov.uk/Reference library/Publications/archive 2001/ci mappin g doc 2001.htm

Deleuze, G (1988) Bergsonism, Zone Books, New York.

Dixon, R (2008) Q\&A: Michelin stars, The Guardian.

Dörfler, V \& Ackermann, F (2012) Understanding Intuition: The Case for Two Forms of Intuition, Management Learning, 43(5): 545-564. http://dx.doi.org/10.1177/1350507611434686

Dörfler, V, Baracskai, Z \& Velencei, J (2009) Knowledge Levels: 3-D Model of the Levels of Expertise, AoM 2009: The $69^{\text {th }}$ Annual Meeting of the Academy of Management, 7-11 August 2009, Chicago, IL.

Dörfler, V, Baracskai, Z \& Velencei, J (2010) Understanding Creativity, Transactions on Advanced Research, 6(2): 18-26. http://tar.ipsitransactions.org/2010/July/Paper\%2004.pdf

Dörfler, V \& Stierand, M (2009) Investigating the Extraordinary, BAM 2009, 15-17 September 2009, Brighton.

Dreyfus, HL \& Dreyfus, SE (2000) Mind over Machine, The Free Press, New York, NY.

Enz, C \& Harrison, J (2008) Innovation and Entrepreneurship in the Hospitality Industry, Brotherton, B \& Wood, R The Sage Handbook of Hospitality Management, Sage, London: 213-227.

Enz, C \& Siguaw, J (2004) Revisiting the Best of the Best: Innovations in Hotel Practice, Cornell Hotel and Restaurant Administration Quarterly, 44(5): 115-123. http://dx.doi.org/10.1016/S0010-8804(03)90115-7

Faullant, R, Schwarz, E, Krajger, I \& Breitenecker, R (2012) Towards a Comprehensive Understanding of Lead Userness: The Search for Individual Creativity, Creativity and Innovation Management, 21(1): 76-92.

Ferguson, P (1998) A Cultural Field in the Making: Gastronomy in the 19th Century France, American Journal of Sociology, 104: 597-641.

Ferguson, P (2004) Accounting for Taste: The Triumph of French Cuisine, University of Chicago Press, Chicago, IL.

Fine, G (1992) The Culture of Production: Aesthetic Choices and Constraints in Culinary Work, The American Journal of Sociology, 97(5): 1268-1294.

Fine, G (1996) Justifying Work: Occupational Rhetorics as Resources in Restaurant Kitchens, Administrative Science Quarterly, 41: 90-115. 
Finlay, L (2008) Introducing Phenomenological Research (unpublished), 1-9 pages. Electronic version: http://www.lindafinlay.co.uk/phenomenology.htm

Gallos, JV (2009) Creativity Forums: Learning from the Lives of Extraordinary Leaders, Organization Management Journal, 76 (2): http://proquest.umi.com/pqdweb?did=1806431501\&Fmt $=7 \&$ clientld $=46002 \& R Q T=$ 309\&VName=PQD

Gardner, H (1998) Extraordinary Minds, Phoenix, London.

George, JM (2007) 9 Creativity in Organizations, The Academy of Management Annals, 1(1): 439-477. http://dx.doi.org/10.1080/078559814

Giorgi, A (1985) Sketch of a psychological phenomenological method, Giorgi, A Phenomenology and psychological research, Duquesne University Press, Pittsburgh, PA: 8-22.

Giorgi, A (1994) A phenomenological perspective on certain qualitative research methods, Journal of Phenomenological Psychology, 25: 190-220.

Gobet, F \& Simon, HA (2000) Five seconds or sixty? Presentation time in expert memory, Cognitive Science, 24(4): 651-682.

Grant, AM, Dutton, JE \& Rosso, BD (2008) Giving commitment: Employee support programs and the prosocial sensemaking process, Academy of Management Journal, 51(5): 898918.

Guilford, J (1950) Creativity, American Psychologist, 5(9): 444-454. https://www.ncbi.nlm.nih.gov/pubmed/14771441

Harrington, R (2004) Part I: The Culinary Innovation Process - A Barrier to Imitation, Journal of Foodservice Business Research, 7(3): 35-57.

Hennessey, BA \& Amabile, TM (2010) Creativity, Annual Review of Psychology, 61(1): 569-598. http://www.annualreviews.org/doi/abs/10.1146/annurev.psych.093008.100416

Hon, A (2011) Enhancing employee creativity in the Chinese context: The mediating role of employee self-concordance, International Journal of Hospitality Management, 30: 375-384.

Horng, J-S \& Hu, M-LM (2008) The Mystery in the Kitchen: Culinary Creativity, Creativity Research Journal, 20(2): 221-230.

Horng, J-S \& Hu, M-LM (2009) The Creative Culinary Process: Constructing and Extending a Four-Component Model Creativity Research Journal, 21(4): 376 - 383

Horng, J-S \& Lee, Y-C (2009) What environmental factors influence creative culinary studies?, International Journal of Contemporary Hospitality Management, 21(1): 100-117. 
Huber, G (1998) Synergies Between Organizational Learning and Creativity \& innovation, Organizational Learning and Creativity \& Innovation 7(1): 3-8.

Husserl, E (1960) Cartesian meditations, M. Nijhoff The Hague.

Ibarra, H (1999) Provisional selves: experimenting with image and identity in professional adaptation, Administrative Science Quarterly, 44(4): 764-791.

Im, S, Montoya, MM \& Workman, JP (2013) Antecedents and Consequences of Creativity in Product Innovation Teams, Journal of Product Innovation Management.

Jeong, HS \& Brower, RS (2008) Extending the Present Understanding of Organizational Sensemaking Three Stages and Three Contexts, Administration \& Society, 40(3): 223252.

Johansson, F (2006) The Medici Effect. What elephants and epidemics can teach us about innovation, Harvard Business School Press, Boston, MA.

Kabanoff, B \& Rossiter, JR (1994) Recent developments in applied creativity, International review of industrial and organizational psychology, 9: 283-283.

Keogh, W \& McAdam, R (2004) Transitioning Towards Creativity and Innovation Management in SMEs, Creativity and Innovation Management, 13(2): 126-139.

Krishnan, V \& Ulrich, KT (2001) Product development decisions: A review of the literature, Management Science, 47(1): 1-21.

Lane, C (2010) The Michelin-starred restaurant sector as a cultural industry: a cross-national comparison of restaurants in the UK and Germany, Food, Culture and Society: An International Journal of MultidisciplinaryResearch, 13(4): 493-519.

Lane, C (2013) Taste makers in the "fine-dining" restaurant industry: The attribution of aesthetic and economic value by gastronomic guides, Poetics, 41(4): 342-365. http://dx.doi.org/10.1016/i.poetic.2013.05.003

Mason, RO \& Mitroff, II (1973) A program for research on management information systems, Management Science, 19(5): 475-487.

Messeni Petruzzelli, A \& Savino, T (2012) Search, Recombination, and Innovation: Lessons from Haute Cuisine, Long Range Planning.

Michelin (2012) Michelin Guide [Electronic Version]. Retrieved 9 September 2013.

NOIE (2003) Creative Industries Cluster Study. Retrieved. from http://www.govonline.gov.au/publications/NOIE/DCITA/cluster study report 28ma y.pdf.

Norlander, T \& Gustafson, R (1997) Effects of alcohol on picture drawing during the verification phase of the creative process, Creativity Research Journal, 10: 355-362. 
Norlander, T \& Gustafson, R (1998) Effects of alcohol on a divergent fluency test during the illumination phase of the creative process, Creativity Research Journal, 11: 265-274.

Orfila-Sintes, F, Crespí-Cladera, R \& Martínez-Ros, E (2005) Innovation activity in the hotel industry: Evidence from Balearic Islands, Tourism Management, 26(6): 851-865.

Orfila-Sintes, F \& Mattsson, J (2009) Innovation Behaviour in the hotel industry, Omega, 37: 380-394.

Osbeck, LM (1999) Conceptual Problems in the Development of a Psychological Notion of "Intuition", Journal for the Theory of Social Behaviour, 29(3): 229-249. http://www.blackwell-synergy.com/doi/abs/10.1111/1468-5914.00100

Osbeck, LM (2001) Direct Apprehension and Social Construction: Revisiting the Concept of Intuition, Journal of Theoretical and Philosophical Psychology, 21(2): 118-131. http://soe.indstate.edu/div24/JTPP\%20Aticles/21-2/the202.pdf

Ottenbacher, MC (2007) Innovation management in the hospitality industry: different strategies for achieving success, Journal of Hospitality \& Tourism Research, 31(4): 431454.

Ottenbacher, MC \& Gnoth, J (2005) How to develop successful hospitality innovation, Cornell Hotel and Restaurant Administration Quarterly, 46(2): 205-222.

Ottenbacher, MC \& Harrington, R (2007) The innovation development process of Michelinstarred chefs, International Journal of Contemporary Hospitality Management, 19(6): 444-460.

Özbilgin, MF (2011) Continuity and change: improving our service to the BJM community and moving towards contextual studies of management, British Journal of Management, 22(1): 1-3.

Paget, E, Dimanche, F \& Mounet, J-P (2010) A Tourism Innovation Case - An Actor-Network Approach, Annals of Tourism Research, 37(3): 828-847.

Peterson, Y \& Birg, L (1988) Top Hat: The Chef as Creative Occupation, Free Inquiry in Creative Sociology, 16: 67-72.

Petruzzelli, AM \& Savino, T (2014) Search, Recombination, and Innovation: Lessons from Haute Cuisine, Long Range Planning, 47(4): 224-238. http://dx.doi.org/10.1016/j.Irp.2012.09.001

Pil, FK \& Cohen, SK (2006) Modularity: Implications for imitation, innovation, and sustained advantage, Academy of Management Review, 31(4): 995-1011.

Pohlmann, M (2005) The Evolution of Innovation: Cultural Backgrounds and the Use of Innovation Models, Technology Analysis \& Strategic Management, 17(1): 9-19.

Polányi, M (1969) Knowing and Being, University of Chicago Press, Chicago, IL. 
Popper, KR (1968/2004) The Logic of Scientific Discovery (2 ${ }^{\text {nd }}$ ed.), Routledge, London, UK.

Rao, H, Monin, P \& Durand, R (2003) Institutional Change in Toque Ville: Nouvelle Cuisine as an Identity Movement in French Gastronomy, American Journal of Sociology, 108(4): 795-843.

Robinson, R \& Beesley, L (2010) Linkages between creativity and intention to quit: An occupational study of chefs, Tourism Management, 31: 765-776.

Rodgers, S (2007) Innovation in food service technology and its strategic role, International Journal of Hospitality Management, 26(4): 899-912.

Rodgers, S (2008) Technological innovation supporting different food production philosophies in the food service sectors, International Journal of Contemporary Hospitality Management, 20(1): 19-34.

Rooney, C (2004) From the universal to the cosmic - The surroundings of Beau Travail, Journal of European Studies, 34(1/2): 106-127.

Runco, M (2006) Reasoning and Personal Creativity, Kaufman, J \& Baer, J Creativity and Reason in Cognitive Development, Cambridge University Press, Cambridge: 99-116.

Sadler-Smith, E (2008) Inside Intuition, Routledge, London, UK.

Sawyer, RK (2006) Explaining Creativity: The Science of Human Innovation: The Science of Human Innovation, Oxford University Press, USA

Schatzman, L \& Strauss, A (1973) Field Research: Strategies for a Natural Sociology, Prentice Hall, Englewood Cliffs.

Simon, HA (1973) The structure of ill structured problems, Artificial Intelligence, 4(3-4): 181$201 . \quad \quad$ http://www.sciencedirect.com/science/article/B6TYF-4810SCJ$\underline{1 H / 2 / 2 a 1 d 2760 f 17 e c d b a 0541 c 9 d 0 a 3885 d f 9}$

Simon, HA (1987) Making Management Decisions: the Role of Intuition and Emotion, Academy of Management Executive, 1(1): 57-64. http://dx.doi.org/10.5465/AME.1987.4275905

Sinclair, M (2011) An Integrated Framework of Intuition, Sinclair, M Handbook Of Intuition Research, Edward Elgar Publishing, Cheltenham, UK: 3-16. http://dx.doi.org/10.4337/9780857936370

Song, M \& Swink, M (2002) Marketing-manufacturing joint involvement across stages of new product development: Effects on the success of radical vs. incremental innovations, Marketing-manufacturing joint involvement across stages of new product development: Effects on the success of radical vs. incremental innovations: B1-B6.

Stierand, M (2013) Gastronomy and Haute Cuisine, Wood, RC Key Concepts in Hospitality Management SAGE Publications, London, UK: 50-54. 
Stierand, M \& Dörfler, V (2011a) Methods against Methods, Mesquita, A Technology for Creativity and Innovation: Tools, Techniques and Applications, IGI Global, Hershey, PA: 121-134. http://dx.doi.org/10.4018/978-1-60960-519-3.ch006

Stierand, M \& Dörfler, V (2011b) Revising the Notion of Sample Representativeness, BAM 2011: The Twenty-fifth Annual Conference of the British Academy of Management, 1315 September, 2011, Birmingham, UK. (accessed 2011)

Stierand, M \& Dörfler, V (2012) Reflecting on a Phenomenological Study of Creativity and Innovation in Haute Cuisine, International Journal of Contemporary Hospitality Management, 24(6): 946-957. http://dx.doi.org/10.1108/09596111211247254

Stierand, M \& Dörfler, V (2013) The Experience of Personal Creativity: Unpacking Its Underlying Structure in the Creative Industries, AoM 2013: The Seventy-third Annual Meeting of the Academy of Management, January 1, 2013, Lake Buena Vista (Orlando), FL. Electronic version: http://dx.doi.org/10.5465/AMBPP.2013.11305abstract

Stierand, M \& Lynch, P (2008) The Art of Creating Culinary Innovations, Tourism and Hospitality Research, 8(4): 337-350. http://dx.doi.org/10.1057/thr.2008.28

Styhre, A, Wikmalm, L, Olilla, S \& Roth, J (2010) Garbage-Can Decision Making and the Accommodation of Uncertainty in New Drug Development Work, Creativity and Innovation Management, 19(2): 134-146.

Surlemont, B \& Johnson, C (2005) The role of guides in artistic industries - The special case of the "star system" in the haute-cuisine sector, Managing Service Quality, 15(6): 577590.

Svejenova, S (2005) 'The Path with the Heart': Creating the Authentic Career, Journal of Management Studies, 42(5): 947-974.

Svejenova, S, Mazza, C \& Planellas, M (2007) Cooking Up Change in Haute Cuisine: Ferran Adrià as an Institutional Entrepreneur, Journal of Organizational Behavior, 28(5): 539561.

Svejenova, S, Planellas, M \& Vives, L (2010) An Individual Business Model in the Making: a Chef's Quest for Creative Freedom, Long Range Planning, 43: 408-430.

Svejenova, S, Slavich, B \& Abdel-Gawad, S (2012) Business models of creative entrepreneurs, the case of haute cuisine chefs, Jones, C, Lorenzen, M \& Sapsed, J Handbook of Creative Industries, Oxford University Press, Oxford.

Tsoukas, H (2005) Complex Knowledge: Studies in Organizational Epistemology, Oxford University Press, Oxford.

Vaughan, FE (1979) Awakening Intuition, Anchor Books, New York, NY.

Wallas, G (1926) The arts of thought, Harcourt, Brace and World, New York, NY. 
Weick, KE (2001) Making Sense of the Organization, Blackwell Publishers, Oxford, UK.

Weick, KE, Sutcliff, KM \& Obstfeld, D (2005) Organizing and the process of sensemaking, Organization Science, 16(4): 409-421.

Wittgenstein, L (1979) On Certainty, Blackwell, Oxford.

Wong, C-k \& Pang, W-L (2003) Barriers to creativity in the hotel industry - perspectives of managers and supervisors, International Journal of Contemporary Hospitality Management, 15(1): 29-37.

Wong, S \& Ladkin, A (2008) Exploring the relationship between employee creativity and jobrelated motivators in the Hong Kong hotel industry, International Journal of Hospitality Management, 27: 426-437.

Wong, S \& Pang, L (2003) Motivators to creativity in the hotel industry - perspectives of managers and supervisors, Tourism Management, 24: 551-559.

Woodward, K \& Stierand, M (2014) 'Stars War': Conflicts between Chefs and Restaurant Guides, Pantelidis, IS The Routledge Handbook of Hospitality Management, Routledge, London, UK: 227-236.

Yang, K (2007) Firms' network position: Industry hierarchy position and innovation and an additional example of equivalent block models and between-sector position, Firms' network position: Industry hierarchy position and innovation and an additional example of equivalent block models and between-sector position: 1-6.

Zaltman, G, Duncan, R \& Holbek, J (1973) Innovations and organisations, John Wiley \& Sons, New York. 